\title{
Of mice and people
}

Josep Dalmau, MD, PhD

Correspondence to

Dr. Dalmau:

jdalmau@clinic.ub.es

Neurol Neuroimmunol Neuroinflamm

2016;3:e282; doi: 10.1212/ NXI.0000000000000282
N2 often includes articles on mouse models and therefore the title of this Corner would be applicable to most N2 issues. Animal models represent the quintessence of translational research and are invaluable tools in neuroscience research. Modeling starts with a basic understanding of a human disease translated into a model that, if successful, will lead researchers back to the clinics armed with new theories and therapeutic possibilities. In the current issue of $\mathrm{N} 2$, there are several studies that exemplify the power of animal modeling to link the laboratory to the clinics.

Laquinimod is a quinolone-3-carboxamide that is being developed for the treatment of multiple sclerosis (MS), but its underlying therapeutic mechanisms are poorly understood. Studies have shown that laquinimod promotes development of type II myeloid antigen-presenting cells, which inhibit development of proinflammatory Th1 and Th17 cells. ${ }^{1}$ Varrin-Doyer et al. ${ }^{2}$ investigated whether laquinimod could also exert activity on several B-cell activities that contribute to CNS autoimmunity. These authors evaluated the effects of laquinimod on 2 experimental autoimmune encephalomyelitis (EAE) models that require B-T cell cooperation. In the recombinant myelin oligodendrocyte glycoprotein (MOG)-induced EAE model, they showed that laquinimod interfered with development of $\mathrm{T}$ follicular helper cells (Tfh, a CD4 T-cell subset that directs B-cell differentiation, germinal center formation, and immunoglobulin class switching), B-cell activation, secretion of MOG-specific antibodies, and EAE. In the spontaneous EAE model developed by crossing MOG-specific T-cell receptor transgenic mice (2D2) with MOG-specific B-cell receptor transgenic mice (Th), laquinimod reduced expansion of Tfh cells along with accumulation of meningeal B-cell aggregates, and inhibited disability progression when treatment was initiated after mice developed paralysis. Collectively, these findings may be relevant not only for the use of laquinimod in patients with progressive MS, but also for other antibody-associated disorders of the CNS such as neuromyelitis optica and anti-
NMDA receptor (NMDAR) and other autoimmune encephalitis.

Several studies on EAE have linked different immune mediators with preferential development of brain vs spinal inflammation. ${ }^{3,4}$ In a previous study, Stromnes et al. ${ }^{5}$ showed that parenchymal brain inflammation in EAE was enhanced when the ratio of Th17 cells to interferon (IFN)- $\gamma$-secreting T cells (Th1 cells) was $\geq 1$, whereas a ratio of Th17:Th1 $\leq 1$ associated with inflammation largely restricted to the spinal cord. In the current study, investigators from the same group led by Johnson et al. ${ }^{6}$ analyzed the Th17 and Th1 ex vivo responses to 2 myelin proteins (myelin basic protein [MBP] and MOG) in peripheral blood mononuclear cells (PBMCs) of 3 human groups: patients with relapsing-remitting MS with predominant brain or spinal cord involvement and age-matched healthy controls. Interestingly, MBP and MOG elicited different responses; for MBPspecific responses, a major influence was the low IFN- $\gamma$ response detected for spinal cordpredominant MS, whereas for MOG-specific responses, increased Th17 cells in spinal cordpredominant MS and increased Th1 cells in brainpredominant MS were the main factors in the Th17: Th1 ratios. An interesting question raised by the investigators is whether PBMCs are indicative of effector T-cell activity in the CNS, or if the peripheral T-cell responses reflect the inverse T-cell activity within the CNS because the CNS acts as a "sink" for pathogenic $\mathrm{T}$ cells. The latter would explain the opposite findings comparing the EAE model (where the Th17:Th1 ratio was examined in the CNS) with patients with MS where the T-cell ratios were examined in PBMCs. Future studies should clarify these questions, but results from this study suggest that the localization of lesions in the brain vs the spinal cord of patients with MS associates with different effector T-cell responses to myelin proteins, and possibly distinct pathogenic pathways depending on the area of the CNS that is predominantly affected.

From ICREA-IDIBAPS, Hospital Clínic, University of Barcelona, Spain; and Department of Neurology, University of Pennsylvania, Philadelphia. Funding information and disclosures are provided at the end of the editorial. Go to Neurology.org/nn for full disclosure forms.

This is an open access article distributed under the terms of the Creative Commons Attribution-NonCommercial-NoDerivatives License 4.0 (CC BY-NC-ND), which permits downloading and sharing the work provided it is properly cited. The work cannot be changed in any way or used commercially. 
Identifying relapses vs pseudorelapses in neuromyelitis optica spectrum disorders (NMOSD) has important clinical implications for the type and duration of treatment and avoiding unnecessary immunotherapy and possible side effects. Kessler et al. ${ }^{7}$ examined early indicators of relapses vs pseudorelapses in 74 hospitalizations of patients with NMOSD. Relapses were defined as episodes of worsening symptoms and change in neurologic examination that correlated with new or enhancing MRI abnormalities; pseudorelapses were defined as exacerbation of symptoms but with negative MRI findings and identification of an alternative cause that when treated resulted in neurologic improvement. According to these criteria, 57 hospitalizations were due to confirmed relapses and 17 to pseudorelapses. Worsening visual acuity for more than 24 hours was strongly suggestive of a true relapse; in contrast, pseudorelapses localized to the spinal cord of patients with previous myelitis who otherwise presented as a true relapse but the MRI did not reveal new findings. Age at presentation, sex, race, urinary tract infection, leukocyte count, weakness, numbness, bowel/bladder symptoms, and aquaporin-4 antibody status were not significantly different between relapse and pseudorelapse cases. The authors acknowledged the limitations of the study, including the retrospective collection of data and the lack of inclusion of CSF pleocytosis in the definition of relapse.

Lejuste et al. ${ }^{8}$ examined the psychiatric manifestations of anti-NMDAR encephalitis in a retrospective review of 111 adults with this disorder. In 65 (59\%), the initial symptoms were psychiatric, and 45 (40\%) were first hospitalized in a psychiatric institution. Symptoms included hallucinations, depression, acute schizoaffective episodes, or mania, among others. In $87 \%$ of the patients, this was the first episode of psychiatric symptoms, but some patients had a history of psychiatric episodes that in retrospect were suspected to be anti-NMDAR encephalitis. The median duration of hospitalization in psychiatry units was 9 days (ranging from a few hours to 239 days). Interestingly, 24 of these 45 patients had neurologic signs at the first evaluation, but alternative diagnoses to a primarily psychiatric disorder were not considered. The reasons to transfer the patients from psychiatry to intensive care or other departments were the suspicion of neuroleptic malignant syndrome (NMS) in $47 \%$ of the patients, seizures (22\%), other neurologic symptoms (e.g., amnesia, language dysfunction, 20\%), and other reasons (e.g., EEG, MRI, family request, 11\%). In the entire series, patients who received antipsychotics (typical or atypical) were more likely to develop fever than patients who did not. The authors emphasize the high rate of antipsychotic intolerance in patients with antiNMDAR encephalitis, which in some clinical settings should lead practitioners to suspect this disorder.
Collectively, these findings and some interesting individual examples, such as the case of a patient treated for 1.5 years for schizophrenia who at examination showed pure retrograde amnesia suggesting alternative diagnoses (e.g., anti-NMDAR encephalitis), should lead to reflection and reconsideration of the criteria used for NMS and to a cautious use of the diagnosis of "schizophrenia" in patients harboring antibodies specific for NMDAR encephalitis.

Another interesting study by Zeydan et al. ${ }^{9}$ investigated the effectiveness of infliximab, a tumor necrosis factor- $\alpha$ blocker, for patients with neuro-Behçet syndrome refractory to other immunotherapies. The study included 16 patients with 2 or more neurologic relapses (excluding purely progressive disease). In one patient, infliximab was stopped due to pulmonary and CNS tuberculosis. In the other 15 patients, infliximab treatment abrogated the development of neurologic relapses with no further disability accumulation. These findings provide Class IV evidence that for patients with neuroBehçet refractory to other immunotherapies, infliximab prevents relapses and stabilizes disability.

I hope this preview has piqued your interest to read these and the other equally interesting articles in this issue of $\mathrm{N} 2$.

\section{STUDY FUNDING}

No targeted funding.

\section{DISCLOSURE}

J. Dalmau is the editor of Neurology ${ }^{\circledR}:$ Neuroimmunology \& Neuroinflammation, is on the editorial board for Neurology UpToDate, holds patents for and receives royalties from $\mathrm{Ma} 2$ autoantibody test, NMDA receptor autoantibody test, $G A B A(B)$ receptor autoantibody test, $G A B A(A)$ receptor autoantibody test, DPPX autoantibody test, and IgLON5 autoantibody test, and receives research support from Euroimmun, NIH, Fundació CELLEX, Instituto Carlos III (CIBERER), and Fondo de Investigaciones Sanitarias. Go to Neurology.org/nn for full disclosure forms.

\section{REFERENCES}

1. Schulze-Topphoff U, Shetty A, Varrin-Doyer M, et al. Laquinimod, a quinoline-3-carboxamide, induces type II myeloid cells that modulate central nervous system autoimmunity. PLoS One 2012;7:e33797.

2. Varrin-Doyer M, Pekarek LK, Spencer CM, et al. Treatment of spontaneous EAE by laquinimod reduces Tfh, B cell aggregates and disease progression. Neurol Neuroimmunol Neuroinflamm 2016;3:e272. doi: 10.1212/NXI.0000000000000272.

3. Stoolman JS, Duncker PC, Huber AK, Segal BM. Sitespecific chemokine expression regulates central nervous system inflammation and determines clinical phenotype in autoimmune encephalomyelitis. J Immunol 2014; 193:564-570.

4. Lees JR, Golumbek PT, Sim J, Dorsey D, Russell JH. Regional CNS responses to IFN-gamma determine lesion localization patterns during EAE pathogenesis. J Exp Med 2008;205:2633-2642.

5. Stromnes IM, Cerretti LM, Liggitt D, Harris RA, Goverman JM. Differential regulation of central nervous system autoimmunity by $\mathrm{T}(\mathrm{H}) 1$ and $\mathrm{T}(\mathrm{H}) 17$ cells. Nat Med 2008;14:337-342. 
6. Johnson MC, Pierson ER, Spieker AJ, et al. Distinct T cell signatures define subsets of multiple sclerosis patients. Neurol Neuroimmunol Neuroinflamm 2016;3:e278. doi: 10. 1212/NXI.0000000000000278.

7. Kessler RA, Mealy MA, Levy M. Early indicators of relapses versus pseudorelapses in neuromyelitis optica spectrum disorder. Neurol Neuroimmunol Neuroinflamm 2016;3:e269. doi: 10.1212/NXI.0000000000000269.
8. Lejuste F, Thomas L, Picard G, et al. Neuroleptic intolerance in patients with anti-NMDAR encephalitis. Neurol Neuroimmunol Neuroinflamm 2016;3:e280. doi: 10. 1212/NXI.0000000000000280.

9. Zeydan B, Uygunoglu U, Saip S, et al. Infliximab is a plausible alternative for neurological complications of Behçet's disease. Neurol Neuroimmunol Neuroinflamm 2016;3: e258. doi: 10.1212/NXI.0000000000000258. 


\section{Neurology \\ Neuroimmunology \& Neuroinflammation}

Of mice and people

Josep Dalmau

Neurol Neuroimmunol Neuroinflamm 2016;3;

DOI 10.1212/NXI.0000000000000282

This information is current as of October 6, 2016

Updated Information \&

Services

References

Permissions \& Licensing

Reprints including high resolution figures, can be found at:

http://nn.neurology.org/content/3/5/e282.full.html

This article cites 9 articles, 5 of which you can access for free at: http://nn.neurology.org/content/3/5/e282.full.html\#\#ref-list-1

Information about reproducing this article in parts (figures,tables) or in its entirety can be found online at:

http://nn.neurology.org/misc/about.xhtml\#permissions

Information about ordering reprints can be found online: http://nn.neurology.org/misc/addir.xhtml\#reprintsus

Neurol Neuroimmunol Neuroinflamm is an official journal of the American Academy of Neurology.

Published since April 2014, it is an open-access, online-only, continuous publication journal. Copyright $@$ 2016 American Academy of Neurology. All rights reserved. Online ISSN: 2332-7812.

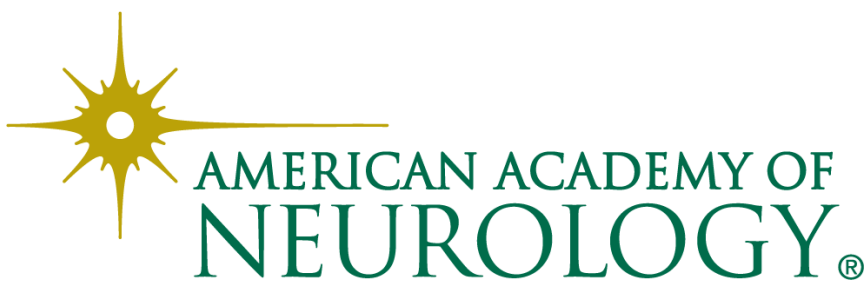

